\title{
The new trauma score (NTS): a modification of the revised trauma score for better trauma mortality prediction
}

Jin Hee Jeong ${ }^{1,3+}$, Yong Joo Park ${ }^{2 \dagger}$, Dong Hoon Kim ${ }^{1,3^{*}}$, Tae Yun Kim ${ }^{1}$, Changwoo Kang ${ }^{1,3}$, Soo Hoon Lee ${ }^{1}$, Sang Bong Lee ${ }^{1}$, Seong Chun Kim ${ }^{1,2}$ and Daesung Lim²

\begin{abstract}
Background: Since its introduction, the Revised Trauma Score (RTS) has been widely used to determine the prognosis of trauma patients. Recent studies have revealed a need to change the parameters of the RTS. We have designed a new trauma score (NTS) based on revised parameters, including the adoption of the actual Glasgow Coma Scale (GCS) score instead of a GCS code, the revision of the systolic blood pressure interval used for the code value and the incorporation of peripheral oxygen saturation $\left(\mathrm{SpO}_{2}\right)$ instead of respiratory rate. The purpose of this study was to evaluate the predictive performance of the NTS for in-hospital mortality compared with the RTS and other trauma scores.

Methods: This was a prospective observational study using data from the trauma registry of a tertiary hospital. The subjects were selected from patients who arrived at the ED between July 1, 2014, and June 30, 2016, and, for external validation purposes, those who arrived at the ED between July 1, 2011, and June 30, 2013. Demographic data and physiological data were analyzed. NTS models were calculated using logistic regression for GCS score, SBP code values, and $\mathrm{SpO}_{2}$. The mortality predictive performance of NTS was compared with that of other trauma scores.

Results: A total of 3263 patients for derivation and 3106 patients for validation were included in the analysis. The NTS showed better discrimination than the RTS (AUC $=0.935$ vs. 0.917, respectively, AUC difference $=0.018, p=0.001 ; 95 \% \mathrm{Cl}$, 0.0071-0.0293) and similar discrimination to that of mechanism, Glasgow Coma scale, age, and arterial pressure (MGAP) and the Glasgow Coma Scale, age, and systolic arterial pressure (GAP). In the validation cohort, the global properties of the NTS for mortality prediction were significantly better than those of the RTS (AUC $=0.919$ vs. 0.906, respectively; AUC difference $=0.013, p=0.013 ; 95 \% \mathrm{Cl}, 0.0009-0.0249)$ and similar to those of the MGAP and GAP.
\end{abstract}

Conclusions: The NTS predicts in-hospital mortality substantially better than the RTS.

Keywords: Trauma severity indices, Injury severity score, Emergency department

\section{Background}

In the 30 years since Champion et al. introduced the Revised Trauma Score (RTS), it has been widely used to assess prognosis in trauma patients. The RTS is a convenient tool for trauma triage and initial severity estimation that does not require sophisticated medical tests or

\footnotetext{
* Correspondence: kloud14@hanmail.net

${ }^{\dagger}$ Equal contributors

'Department of Emergency Medicine, Gyeongsang National University School of Medicine, 15, Jinju-daero 816beon-gil, Jinju-si, Gyeongsangnam-do 52727, Republic of Korea

${ }^{3}$ Institute of Health Sciences, Gyeongsang National University, 15, Jinju-daero 816beon-gil, Jinju-si, Gyeongsangnam-do, Republic of Korea

Full list of author information is available at the end of the article
}

devices and is especially useful in prehospital and emergency department (ED) settings. This physiological scoring system consists of the Glasgow Coma Scale (GCS), systolic blood pressure (SBP) and respiratory rate (RR). The parameters are converted to coded values $(0,1,2,3$ or 4$)$ assigned by specified ranges. Each value is multiplied by a weighted coefficient before it is added (Table 1) [1]. The RTS is calculated using the following equation:

RTS $=(0.9368 \times$ GCS code value $)+(0.7326 \times$ SBP code value $)+(0.2908 \times$ RR code value $)$.

The Trauma and Injury Severity Score (TRISS), developed in 1987 by Boyd et al., has been used worldwide to predict trauma survival. The TRISS consists of physiological 
Table 1 Modification of the Revised Trauma Score

\begin{tabular}{|c|c|c|c|c|c|c|}
\hline \multicolumn{4}{|c|}{ Revised Trauma Score } & \multicolumn{3}{|c|}{ New Trauma Score } \\
\hline $\begin{array}{l}\text { Glasgow Coma } \\
\text { Scale }\end{array}$ & $\begin{array}{l}\text { Systolic Blood } \\
\text { Pressure }\end{array}$ & $\begin{array}{l}\text { Respiratory } \\
\text { Rate }\end{array}$ & $\begin{array}{l}\text { Coded } \\
\text { Value }\end{array}$ & $\begin{array}{l}\text { Glasgow Coma } \\
\text { Scale }\end{array}$ & $\begin{array}{l}\text { Systolic Blood } \\
\text { Pressure }\end{array}$ & $\begin{array}{l}\text { Oxygen } \\
\text { saturation }\end{array}$ \\
\hline $13-15$ & $>89$ & $10-29$ & 4 & $3-15$ & $110-149$ & $\geq 94$ \\
\hline $9-12$ & $76-89$ & $>29$ & 3 & & $\geq 150$ & $80-93$ \\
\hline $6-8$ & $50-75$ & $6-9$ & 2 & & $90-109$ & $60-79$ \\
\hline $4-5$ & $1-49$ & $1-5$ & 1 & & $70-89$ & $40-59$ \\
\hline 3 & 0 & 0 & 0 & & $<70$ & $<40$ \\
\hline
\end{tabular}

(RTS) and anatomical scores (Injury Severity Score, ISS) and age, stratified by the injury mechanism (blunt or penetrating trauma) [2]. The TRISS showed substantially improved predictive power of survival for trauma patients over that of the RTS and was validated in subsequent studies $[3,4]$. Despite the complicated calculation and its inapplicability for triage, the TRISS remains the most widely used and prominent survival predictor for research in the quality control of trauma management and prevention.

The Mechanism, GCS, and Age and Arterial Pressure (MGAP) score is a recently developed physiological trauma scoring system. Similar to the TRISS, the MGAP utilized mechanism and age, which are important variables that affect the prognosis of trauma patients. The final scores can be easily obtained after the simple addition of several numbers. While the GCS is transformed to a code value ranging from 0 to 4 in the RTS, the MGAP consists of the actual GCS score with no variation due to its highly informative value and relatively unbiased calculation. Additionally, a SBP of $120 \mathrm{mmHg}$ was chosen for the threshold, whereas $90 \mathrm{mmHg}$ is the first cutoff for decreasing the code value in the RTS [5]. The GCS, Age and Systolic Arterial Pressure (GAP) is a scoring system that was simplified by deleting the mechanism from the MGAP [6]. The MGAP and GAP were shown to be superior to the RTS in mortality prediction of trauma patients. However, they remain inferior to the TRISS.

Uncontrolled hemorrhage is a major leading cause of traumatic injury that is responsible for $35 \%$ of prehospital deaths and over $40 \%$ of deaths within the first $24 \mathrm{~h}$ [7]. Traditionally, a SBP of $<90 \mathrm{mmHg}$ has been a widely accepted threshold for hypotension. The American College of Surgeons Committee on Trauma and National Expert Panel on Field Triage recommends a SBP of $<90 \mathrm{mmHg}$ for specialized trauma centers $[8,9]$. Recently, the concept of a SBP of $<90 \mathrm{mmHg}$ as an early indicator of hypotension in trauma patients has become controversial. SBPs of 90$109 \mathrm{mmHg}$ in the ED or the operating room result in worse outcomes than higher SBPs [10]. Furthermore, in a large population cohort study using data from the Trauma Audit and Research Network $(n=47,927)$, a SBP of $<110 \mathrm{mmHg}$ was identified as a cut off for hypotension, at which a significant increase in mortality occurred [11].
Instead of the recommended formal measurement technique of $1 \mathrm{~min}$, the RR is commonly assessed during a short period of less than $30 \mathrm{~s}$ [12]. In the prehospital and ED settings, exact RR measurement by auscultation for $1 \mathrm{~min}$ is challenging due to patient conditions, loud noises and psychological or emotional pressures on medical personnel. Short RR counting for a 30-s interval is naturally inaccurate compared to a one-minute interval [13]. Recent research has shown that RR measurements obtained by triage nurses using an electronic device in the ED are inaccurate [14]. The same results were found in another study of medical doctors working at a teaching hospital who had been taught accurate measurement techniques immediately before the study [15]. Pulse oximetry is a popular monitoring method widely used in various settings [16-20]. Peripheral oxygen saturation $\left(\mathrm{SpO}_{2}\right)$ is an objective, efficient and unequivocal parameter for screening patient pulmonary function $[21,22]$. Practically, $\mathrm{SpO}_{2}$ has become a substitute for the RR in the past decade. Accordingly, we speculated that $\mathrm{SpO}_{2}$ could be a better component than the RR for trauma mortality prediction.

The RTS is a widely valued but somewhat outdated scoring system for trauma mortality prediction. Therefore, we modified the RTS and designed a new trauma score based on recent developments in the trauma setting. The main ideas include (i) the adoption of the actual GCS score instead of a GCS code, (ii) the revision of the systolic blood pressure interval used for the code value and (iii) the incorporation of $\mathrm{SpO}_{2}$ instead of $\mathrm{RR}$. The details are represented in Table 1 . We termed this measure the New Trauma Score (NTS).

The purpose of this study was to evaluate the predictive performance of the NTS for in-hospital mortality compared to the RTS, MGAP and GAP as well as to provide a proper triage tool during the initial phase of trauma management.

\section{Methods}

Study design and participants

This is a prospectively recorded registry-based observational study using data from the trauma registry of a tertiary hospital located in Jinju, Republic of Korea. Data collection started on July 1, 2011 and was recorded by 
professional heath information managers in our ED. Demographic data, age, gender and physiological data regarding the initial presentation to the ED, as well as outcome and in-hospital mortality, were automatically transferred to the trauma registry from the electronic medical record. Injury mechanisms were categorized as blunt trauma, penetrating trauma, burn, drowning, hanging, asphyxia, poisoning and heat or cold-related injury. Abbreviated Injury Scales (AIS) were calculated according to clinical presentation, imaging results, intervention findings and operative records. Injury descriptions and scoring procedures were fully supervised by emergency physicians. The trauma registry was originally developed as a part of Emergency Departmentbased Injury In-depth Surveillance conducted by the Korea Centers for Disease Control and Prevention. Informed consent was not needed because the data were collected without identifiable personal information. Data used for derivation were obtained from patients arriving in the ED between July 1, 2014 and June 30, 2016. The inclusion criteria consisted of (i) patients categorized with blunt or penetrating mechanisms and (ii) age $\geq 15$ years. The exclusion criteria consisted of (i) patients who died before ED arrival, (ii) patients discharged or transferred from the ED. We used the data from patients arriving at the same hospital between July 1, 2011 and June 30, 2013 for external validation purposes. This study was approved by the Gyeongsang National University hospital institutional review board (number 2016-09-008).

\section{Development of NTS}

To compare the value of the GCS codes used in the RTS and the actual GCS score, we plotted frequency charts for in-hospital mortality (Fig. 1a, b). Using the group with a score of 4 as a reference, the odds ratios of GCS codes of $3,2,1$, and 0 were calculated as categorical variables in the univariate regression. The actual GCS scores were entered into the logistic regression as continuous variables. Both parameters were significant and were used in the next step.

The patient distribution showed a bimodal rather than linear correlation between SBP and death (Fig 1c). We chose $110-149 \mathrm{mmHg}$ as the range for a score of 4 , and $\mathrm{SBP} \geq 150 \mathrm{mmHg}$ received a score of 3 . Blood pressure measurement of trauma victims is very challenging in prehospital or ED triage settings, especially when patients are exsanguinating and progressing to profound shock. It might be impractical for clinical decision making if the interval boundaries are set too low. For that reason, we chose $70 \mathrm{mmHg}$ as the lowest cutoff, and half of the interval (SBP $90 \mathrm{mmHg}$ ) was set as another cutpoint. The $\mathrm{SpO}_{2}$ was divided into five categories, $\geq 94 \%$, $80-93 \%, 60-79 \%, 40-59 \%$ and $<40 \%$ (Fig 1d). Because no references are available to determine $\mathrm{SpO}_{2}$ interval ranges related to trauma mortality prediction, we must depend on clinical experience.

\section{Data analysis}

We performed multiple imputation using multivariate imputation by chained equation (MICE) to impute missing values [23]. The number of multiple imputations should reach the percentage of the missing proportion [24]. In our data set, the ISS was the most frequently missing variable $(8.9 \%$ and $7.9 \%$ in the derivation and validation cohorts, respectively), followed by $\mathrm{SpO}_{2}(3.2 \%$ and $2.8 \%$ ), SBP, RR, and GCS (not exceeding $0.1 \%$ in both cohorts). Therefore, we conducted ten imputations using a predictive mean-matching method for all variables included in the RTS, MGAP, GAP, and the NTS. Age, gender, the ISS and the outcome variable (in-hospital mortality) were also included in the imputation model.

The $x^{2}$ test and the Mann-Whitney $U$ test (because all the continuous data showed non-normal distribution) were used to describe demographic and physiological characteristics of the derivation and validation groups.

A univariate analysis was performed on the GCS score, $\mathrm{SBP}, \mathrm{RR}, \mathrm{SpO}_{2}$, and the coded GCS value. Multivariate logistic regression was conducted using the GCS score, SBP and RR, $\mathrm{SpO}_{2}$ as continuous variables and using the GCS score, SBP and $\mathrm{SpO}_{2}$. We categorized the SBP and $\mathrm{SpO}_{2}$ and assigned code values of $0,1,2,3$ or 4 (Table $1)$. Multivariate logistic regression was performed using the actual GCS score, the coded SBP $\left(\mathrm{SBP}_{\mathrm{NTS}}\right)$ and $\mathrm{SpO}_{2}$ $\left(\mathrm{SpO}_{2 \mathrm{NTS}}\right)$ values, and the coded GCS, SBP $\mathrm{NTS}_{\mathrm{NT}}$, and $\mathrm{SpO}_{2 \mathrm{NTS}}$. Predictive survival (Ps) was calculated using the following equation: Ps $=1 /\left(1+\mathrm{e}^{-\mathrm{b}}\right), \mathrm{b}=\mathrm{b}_{0}+\mathrm{b}_{1} \mathrm{x}$ GCS $+b_{2} \times S B P_{\text {NTS }}+b_{3} \times S p O_{2 N T S} \cdot b_{0}, b_{1}, b_{2}$ and $b_{3}$ were coefficients derived in the regression analysis. The discriminatory ability of the final models was assessed using the receiver operating characteristics (ROC) curve, and calibration was evaluated using the HosmerLemeshow (H-L) statistic. The areas under the ROC curve (AUC) were compared between the NTS, RTS, MGAP and GAP using the nonparametric approach described by DeLong et al. [25]. We deleted the regression coefficients from the NTS to provide an easy triage tool called the NTS for Triage (T-NTS).

The sensitivity and specificity were obtained from the point of the ROC curve. The specificity of NTS was compared to those of RTS, MGAP, GAP, respectively, at the point at which their sensitivity reached $95 \%[4,10]$. We divided patients into four groups according to the TNTS and observed mortality in each group. The final model was validated with separate data using ROC curve analysis to compare our method with the RTS, MGAP and GAP. 


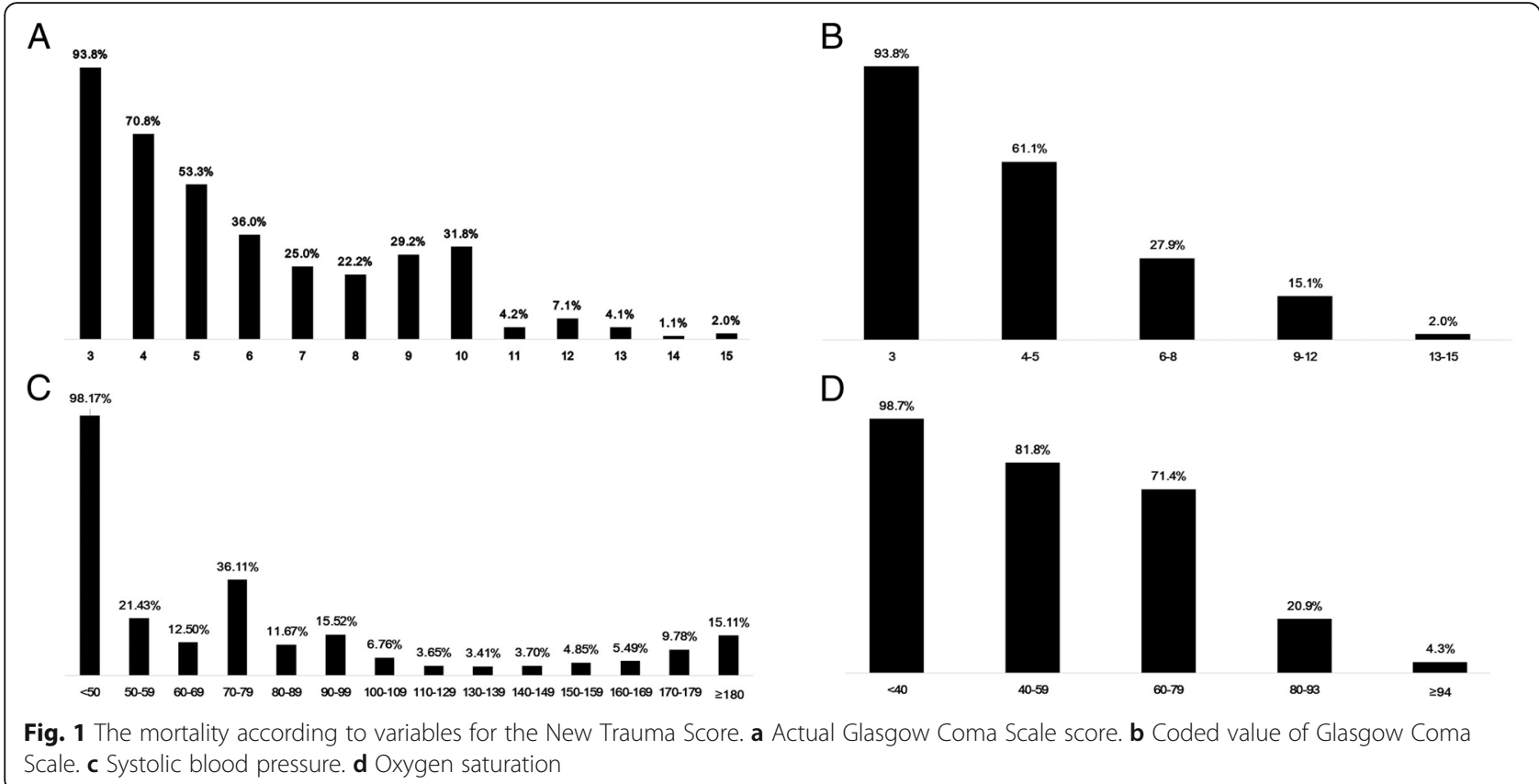

All $p$ values were two-sided, and a value of $p<0.05$ was considered statistically significant. Analyses were performed using MedCalc 17 (MedCalc Software BVBA, Ostend, Belgium) and Stata version 13 (StataCorp, LP, College Station, TX).

\section{Results}

\section{Baseline characteristics}

A total of 24,128 patients were enrolled in the Gyeongsang National University Hospital Trauma Registry between January 2014 and June 2016. Among these patients, 13,862 matched the inclusion criteria (age $\geq 15$ years, blunt or penetrating trauma) for the derivation cohort. Nineteen patients were confirmed dead on ED arrival, and 10,580 were discharged from the ED or transferred to other medical facilities. A total of 3263 patients were finally included for analysis. A total of 12,403 out of 21,461 patients were included in the validation cohort. Fifty-three patients were confirmed dead on ED arrival, and 9244 were discharged from the ED or transferred to other medical facilities. A total of 3106 patients were finally included in the analysis (Fig. 2).

The patients in the derivation cohort had a median age of 60 (IQR, 46-73) years, and $66.0 \%$ were male. A total of 94.4\% suffered from blunt trauma. The median SBP was 130 (IQR, 110-140) $\mathrm{mmHg}$, the median RR was 20 (IQR, 18-20) per minute, the median GCS was 15 (IQR, 15-15) and the median $\mathrm{SpO}_{2}$ was $98 \%$ (IQR, 96\% - 99\%). The median RTS was 7.84 (IQR, 7.84-7.84), and the median ISS was 9 (IQR, 4-13). Overall, the in-hospital mortality rate was $11.3 \%$. Table 2 shows the main demographic characteristics and physiological data of both groups.
Actual GCS vs. coded GCS value in the univariate analysis The mortality prediction of the actual GCS score and the coded GCS value were also compared using univariate logistic regression. The OR of the actual GCS score was $1.62(p<0.001 ; 95 \% \mathrm{CI}, 1.5647-1.6781)$. The ORs of the coded GCS scores of 3, 2, 1, and 0 were 8.56 ( $p<0.001 ; 95 \%$ CI, 5.1683-14.1706), 22.77 ( $p<0.001$; 95\% CI, 13.5975-38.1538), $60.87(p<0.001 ; 95 \% \mathrm{CI}$, 34.4921-107.4113), and 757.67( $p<0.001 ; 95 \% \mathrm{CI}$, 402.4326-1426.4840), respectively. These results were included to show which parameter was superior. After further analysis, we eventually chose to use the actual GCS score because it contributed to better calibration of the final model. While the conclusions were drawn in the final step of the analysis, we dropped the coded GCS value in next subsection.

\section{$\mathrm{SpO}_{2}$ vs. respiratory rate}

The GCS score, SBP, RR and $\mathrm{SpO}_{2}$ were entered into the univariate logistic regression as continuous variables, and all of them showed significance. To evaluate the predictive ability of the multivariate model, RR and $\mathrm{SpO}_{2}$ was entered separately with GCS and SBP. The adjusted ORs of RR and $\mathrm{SpO}_{2}$ were $1.01(p=0.974 ; 95 \%$ CI, 0.9648-1.0378) and $1.07(p<0.001 ; 95 \%$ CI, $1.0372-$ 1.0956), respectively (Table 3 ).

Multivariate analysis of $\mathrm{SBP}_{\mathrm{NTS}}, \mathrm{SpO}_{2 \mathrm{NTS}}$, and actual GCS vs. $\mathrm{SBP}_{\mathrm{NTS}}, \mathrm{SpO}_{2 \mathrm{NTS}}$, and coded GCS value

$\mathrm{SBP}_{\mathrm{NTS}}, \mathrm{SpO}_{2 \mathrm{NTS}}$, and the actual GCS reached statistical significance in the multivariate logistic regression. The global predictive performance exhibited good discrimination 

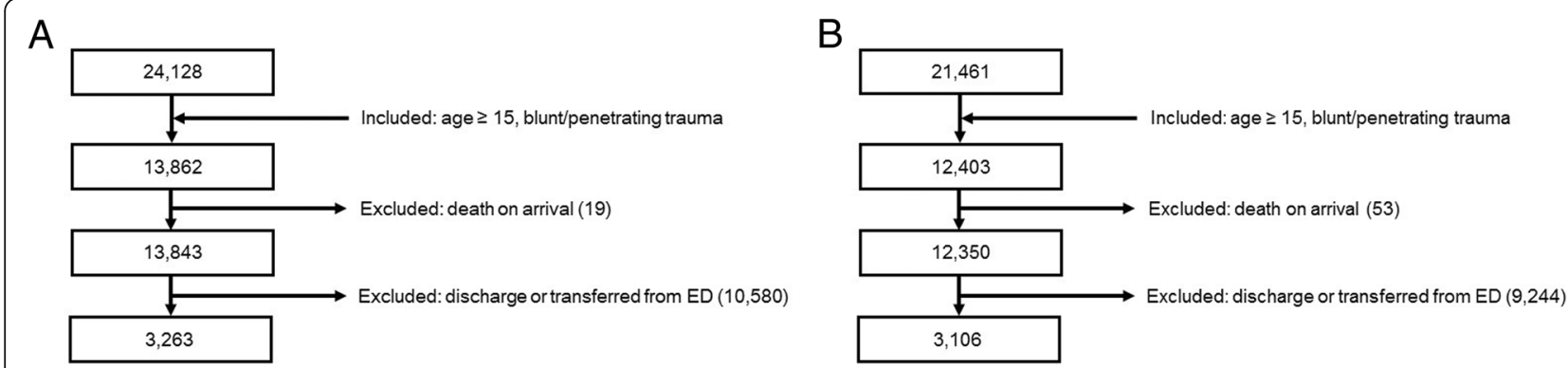

Fig. 2 Patient flow according to inclusion and exclusion criteria. a Derivation cohort. b Validation cohort

$(\mathrm{AUC}=0.935, p<0.001 ; 95 \% \mathrm{CI}, 0.9174-0.9526)$ and calibration ( $\mathrm{H}-\mathrm{L} X^{2}=6.303, p=0.178$; Table 4). SBP $\mathrm{NTS}_{\mathrm{NT}}$ $\mathrm{SpO}_{2 \mathrm{NTS}}$, and the coded value of GCS also showed significance but with less calibration than our final model $(\mathrm{H}-\mathrm{L}$ $\left.X^{2}=18.404, p=0.001\right)$. The following equation was used to calculate Ps: Ps $=1 /\left(1+\mathrm{e}^{-\mathrm{b}}\right), \mathrm{b}=-6.5406+(0.4006 \mathrm{x}$ $\mathrm{GCS})+\left(0.2983 \times \mathrm{SBP}_{\mathrm{NTS}}\right)+\left(0.8709 \times \mathrm{SpO}_{2 \mathrm{NTS}}\right)$. The final NTS model ranged from 1.2019 to 10.6867 and was calculated as follows:

$\mathrm{NTS}=(0.4006 \times \mathrm{GCS})+\left(0.2983 \times \mathrm{SBP}_{\mathrm{NTS}}\right)+(0.8709$ x $\mathrm{SpO}_{2 \mathrm{NTS}}$ ).
The NTS vs. the RTS, the MGAP, the GAP

The NTS showed better discrimination than the RTS (AUC $=0.935$ vs. 0.917, respectively, AUC difference $=0.018, p=0.001 ; 95 \%$ CI, 0. 0071-0. 0293) and a slightly lower AUC than the MGAP (AUC $=0.935$ vs. 0.938, respectively, AUC difference $=0.003, p=0.713$; 95\% CI, -0. 0114-0. 0166) and the GAP (AUC = 0.935 vs. 0.941 , respectively, AUC difference $=0.006$, $p=0.423$; 95\% CI, $-0.0080-0.0190)$. In the validation cohort, the NTS showed better discrimination than the RTS, MGAP, and GAP (Table 5).

Table 2 Characteristics of the derivation and validation groups

\begin{tabular}{|c|c|c|c|c|}
\hline Characteristics & $\begin{array}{l}\text { Derivation cohort } \\
(N=3263)\end{array}$ & $\begin{array}{l}\text { Missing case } \\
\mathrm{N}, \%\end{array}$ & $\begin{array}{l}\text { Validation cohort } \\
(N=3106)\end{array}$ & $\begin{array}{l}\text { Missing case } \\
\mathrm{N}, \%\end{array}$ \\
\hline Age, yrs., median (IQR) & $60(46-73)$ & $0(0)$ & $59(45-72)^{\mathrm{a}}$ & $0(0)$ \\
\hline Men (\%) & $2155(66.0)$ & $0(0)$ & $2065(66.5)^{b}$ & $0(0)$ \\
\hline \multicolumn{5}{|l|}{ Trauma type, n (\%) } \\
\hline Blunt trauma & $3079(94.4)$ & $0(0)$ & $2944(94.8)$ & $0(0)$ \\
\hline Penetrating trauma & 184(5.6) & $0(0)$ & $162(5.2)$ & $0(0)$ \\
\hline \multicolumn{5}{|l|}{ Physiological parameter, median (IQR) } \\
\hline Systolic blood pressure (mmHg) & $130(110-140)$ & $4(0.1)$ & $135(118-150)^{\mathrm{a}}$ & $0(0)$ \\
\hline Respiratory rate (per a minute) & $20(18-20)$ & $4(0.1)$ & $20(18-20)^{a}$ & $0(0)$ \\
\hline Glasgow Coma Scale & $15(15-15)$ & $3(0.1)$ & $15(15-15)$ & $2(0.1)$ \\
\hline Oxygen saturation (\%) & 98 (96-99) & $105(3.2)$ & $98(96-99)^{a}$ & $87(2.8)$ \\
\hline \multicolumn{5}{|l|}{ Trauma location, n (\%) } \\
\hline Head \& neck injury & $1057(32.4)$ & & $1290(41.5)^{b}$ & \\
\hline Face injury & 739 (22.6) & & $612(19.7)^{b}$ & \\
\hline Chest injury & $857(26.2)$ & & $804(25.9)$ & \\
\hline Abdomen injury & $500(15.3)$ & & $440(14.2)$ & \\
\hline Extremity injury & $1383(42.4)$ & & $1241(40.0)$ & \\
\hline RTS, median (IQR) & $7.84(7.84-7.84)$ & $6(0.2)$ & $7.84(7.84-7.84)$ & $2(0.1)$ \\
\hline ISS, median (IQR) & $9(4-13)$ & $289(8.9)$ & $9(4-14)^{a}$ & $244(7.9)$ \\
\hline Death, n (\%) & $368(11.3)$ & $0(0)$ & $332(10.7)$ & $0(0)$ \\
\hline
\end{tabular}

RTS Revised Trauma Score; ISS Injury Severity Score

${ }^{a} p<0.05$ compared with derivation group using Mann-Whitney $U$ test

${ }^{\mathrm{b}} p<0.05$ compared with derivation group using chi-square test 
Table 3 Univariate and multivariate analysis for Glasgow Coma Scale score, systolic blood pressure, respiratory rate, and oxygen saturation

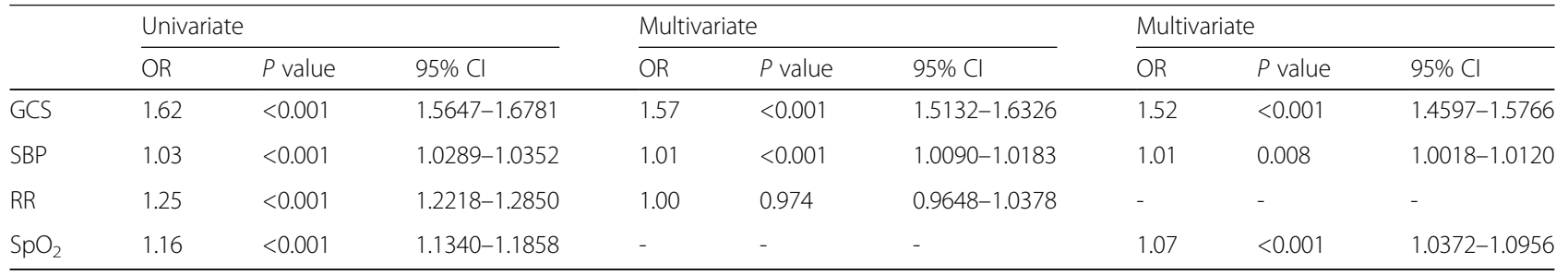

$O R$ odds ratio; $C l$ confidence interval; GCS Glasgow Coma Scale; $S B P$ systolic blood pressure; $R R$ respiratory rate; $S p \mathrm{O}_{2}$ peripheral oxygen saturation

\section{Observed mortality rate according to the NTS for triage (T-NTS) in complete data}

The T-NTS is calculated using the formula $\mathrm{T}$ $\mathrm{NTS}=\mathrm{GCS}+\mathrm{SBP}_{\mathrm{NTS}}+\mathrm{SpO}_{2 \mathrm{NTS}}$. It ranges from 3 to 23. For triage, a T-NTS of 18 , for which the sensitivity and specificity were $95 \%$ and $82 \%$, respectively, was chosen to transfer patients to the trauma center. We categorized the patients into four groups: low (T-NTS 18-23), intermediate (T-NTS 12-17), high (T-NTS 611) and very high (T-NTS 3-5) risk for death. The observed mortality rates of the derivation cohort in each defined stratum were visualized along with those of the validation cohort in Fig. 3. The specificities of the RTS, the MGAP, and GAP were 80\% (cutoff, RTS < 7.0), 80\% (cutoff, MGAP score < 20), and 82\% (cutoff, GAP score $<17)$, respectively.

\section{Discussion}

The aim of our study was to develop a new trauma scoring system based on initial patient physiological data, the GCS score, SBP and $\mathrm{SpO}_{2}$. We found that the NTS significantly outperformed the RTS in mortality prediction of trauma patients but did not exceed the MGAP and GAP. At the fixed rate of $5 \%$ undertriage (sensitivity 95\%), the NTS showed overtriage rate equal to or slightly lower than those of the RTS, MGAP and GAP in our study population. In the trauma setting, a high level of sensitivity rather than specificity for transferring patients to a specialized trauma center is essential to avoid patient deaths due to suboptimal care [8]. Increasing evidence shows that the overtriage of trauma patients leads to large wastes of socioeconomic and medical resources [26]. Lowering the overtriage rate with assurance of a convincing undertriage rate is important. According to

Table 4 Results of logistic regression of GCS, SBP $P_{\text {NTS, }}$ and $\mathrm{SpO}_{2 \mathrm{NTS}}$

\begin{tabular}{llllll}
\hline & $\beta$ & SE & $p$ & $95 \% \mathrm{Cl}$ & \\
\hline Constant & -6.5406 & 0.5805 & 0.000 & -7.6786 & -5.4027 \\
GCS & 0.4006 & 0.0196 & 0.000 & 0.3622 & 0.4391 \\
SBP $_{\text {NTS }}$ & 0.2983 & 0.0754 & 0.000 & 0.1504 & 0.4461 \\
SpO $_{2 \text { NTS }}$ & 0.8709 & 0.1580 & 0.000 & 0.5611 & 1.1808 \\
\hline
\end{tabular}

AUC $=0.935$, Hosmer-Lemeshow $x^{2}=6.303(p=0.178)$ our results, the specificity of the NTS at 95\% sensitivity was over $82 \%$, which is higher than RTS and MGAP and slightly lower than the GAP.

The MGAP and GAP may be superior to the NTS from some perspectives. For example, the components of the MGAP and GAP (mechanism, age, the GCS, and SBP) are immediately available at presentation, whereas the NTS needs $\mathrm{SpO}_{2}$. However, $\mathrm{SpO}_{2}$ measurement is not timeconsuming or expensive in a modern trauma care system. In our study, the AUCs of the MGAP and GAP were larger than that of the NTS in the derivation cohort but were within the scope of statistical error. In the validation cohort, the AUCs of the MGAP and GAP were smaller than that of the NTS but were also within the range of statistical error. Despite the inconclusive results, the superiority of the NTS over the MGAP and GAP was to be expected; the MGAP and GAP already include age and mechanism, whereas the NTS comprises the same element used in the RTS. For this reason, only the NTS can be incorporated into the TRISS, which is the most widely used mortality prediction model for trauma patients. To date, no trauma scoring system has shown better performance than the TRISS. In addition to its use as a triage tool in clinical practice, the NTS may play an important role in trauma research due to its potential applicability as a substitute for the RTS in the TRISS.

We chose to use the actual GCS score rather than the coded GCS, which was initially proposed by Champion et al., in our prediction model. There is no firm evidence of an advantage of the GCS compared with the coded GCS. Among the severity scoring systems used for patients in the intensive care unit, the Acute Physiology and Chronic Health Evaluation (APACHE) uses the actual GCS [27], whereas the Simplified Acute Physiology Score (SAPS) and the Sequential Organ Failure Assessment (SOFA) use the coded GCS value [28, 29]. Most recently developed trauma scoring systems adopt the actual GCS, including the MGAP, GAP, Emergency Trauma Score (EMTRAS), BIG score (composed of base deficit, international normalized ratio, and the GCS), the UK Trauma Audit \& Research Network prediction model, and the corticosteroid randomization after significant head injury (CRASH) model [5, 6, 30-32]. In 
Table 5 Predictive performance of the NTS compared with the RTS, MGAP, and GAP in derivation and validation cohort

\begin{tabular}{|c|c|c|c|c|c|c|c|c|c|c|}
\hline \multirow[t]{2}{*}{ Score } & \multicolumn{5}{|c|}{ Derivation cohort } & \multicolumn{5}{|c|}{ Validation cohort } \\
\hline & AUC & AUC difference & $p$ value & $95 \% \mathrm{Cl}$ & & AUC & AUC difference & $p$ value & $95 \% \mathrm{Cl}$ & \\
\hline NTS & 0.935 & & & & & 0.919 & & & & \\
\hline RTS & 0.917 & 0.018 & 0.001 & 0.0071 & 0.0293 & 0.906 & 0.013 & 0.015 & 0.0009 & 0.0249 \\
\hline MGAP & 0.938 & 0.003 & 0.713 & -0.0114 & 0.0166 & 0.907 & 0.012 & 0.096 & -0.0039 & 0.0271 \\
\hline GAP & 0.941 & 0.006 & 0.423 & -0.0080 & 0.0190 & 0.912 & 0.007 & 0.399 & -0.0090 & 0.0224 \\
\hline
\end{tabular}

our study, the actual GCS showed better calibration of the final model compared with the coded GCS.

The association between SBP and mortality in trauma patients has been assessed in many previous studies. Recent studies have recommended that the SBP threshold be increased up to $110 \mathrm{mmHg}$. Several authors have reported that elevated blood pressure was related to poor outcomes in traumatic brain injury (TBI). Additionally, Zafar et al. and Fuller et al. specifically mentioned that mortality in TBI showed a bimodal distribution [33-36]. In the general trauma population, the association between hypertension and mortality is not clearly known. However, during the initial period of trauma care, whether a given patient has TBI is not certain. To the best of our knowledge, there has been no study regarding this issue. In our population, hypertensive patients (SBP $\geq 150 \mathrm{mmHg}$ ) showed higher mortality than normotensive patients (SBP $\geq 110 \mathrm{mmHg}$; Fig 1c), and we believe this distribution might be caused by the relatively high proportion of head injury in the study patients $(32.4 \%$ of the derivation cohort) (Table 2).

Only one study has assessed the possibility of replacing RR with $\mathrm{SpO}_{2}$ in the RTS (observational cohort study, prehospital setting, $n=1481$ ) [37]. The authors concluded that $\mathrm{RR}$ and $\mathrm{SpO}_{2}$ do not add significant value to other variables in the RTS and TRISS. However, they said the power of the study might be insufficient to detect significance because of abundant missing data (approximately 35\% of RR and $\mathrm{SpO}_{2}$ ). Although it was not advocated in the main conclusion of the study, $\mathrm{SpO}_{2}$ showed larger AUC for mortality compared with the RR (AUC, 0.747 vs. 0.691 ), and the $\mathrm{SpO}_{2}$ was more strongly correlated mortality than the RR was. Our study consistently showed that $\mathrm{SpO}_{2}$ is a better parameter than RR. A major concern regarding the use of $\mathrm{SpO}_{2}$ is nonmeasurability. We could not determine whether missing $\mathrm{SpO}_{2}$ values were caused by non-measurability or were simply missing in our patients. In terms of the retrospective analysis, we believe that this problem was not serious since we imputed the missing $\mathrm{SpO}_{2}$ on significant variables, including the ISS and outcome (in-hospital mortality). However, in clinical practice, nonmeasurable $\mathrm{SpO}_{2}$ leads to a failure to gain the final score. Most non-measurable $\mathrm{SpO}_{2}$ in trauma patients is associated with extremely low oxygenation or poor peripheral circulation caused by profound hemorrhagic shock, tension pneumothorax, cardiac tamponade, or cardiac arrest. Therefore, non-measurable $\mathrm{SpO}_{2}$ could be counted as zero (the lowest code value of the NTS) considering the patients' symptoms, clinical appearance, and other physiological parameters.

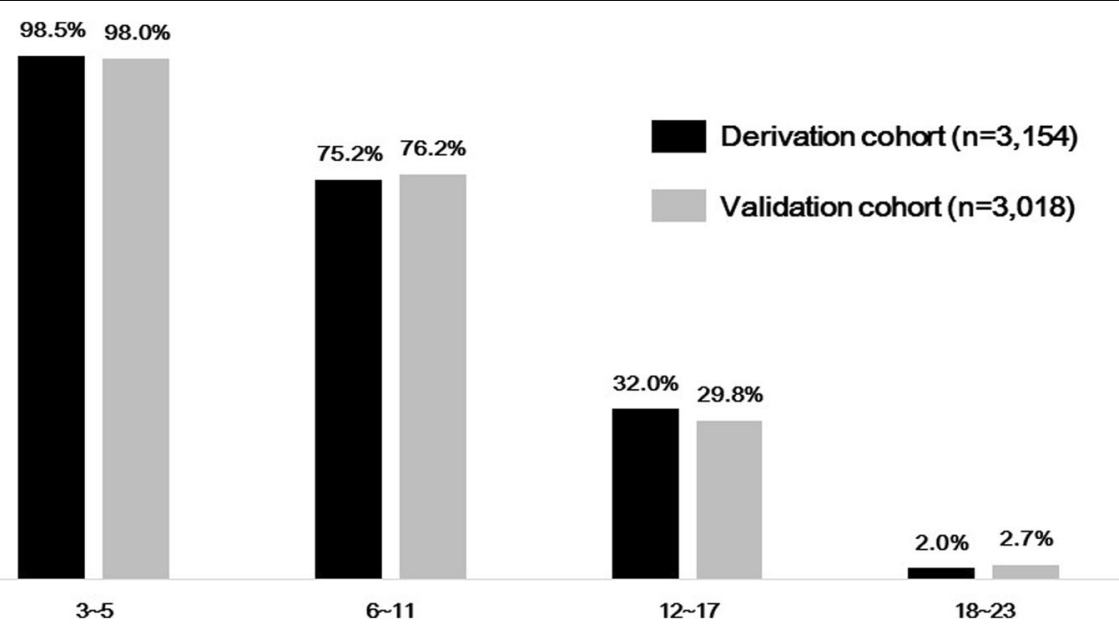

Fig. 3 Observed mortality of low, intermediate, high, and very high risk groups categorized by New Trauma Score for triage in the derivation and validation cohorts 
Our study has some limitations. Of greatest concern is the selection bias. First, patients were transferred to our hospital from a relatively small area of approximately $60 \mathrm{~km}$ in radius. Our hospital is the only tertiary care center for major trauma in this area. Second, this was a single-center study, and therefore generalization could be erroneous. Accordingly, external validation in different populations and countries should be performed. Third, the target population was restricted to adults. Therefore, this score may not be useful for patients under 15 years of age. Because pediatric patients have unique physiological characteristics, separate studies are needed for the development and application of a trauma scoring system for the pediatric population.

\section{Conclusion}

The NTS predicts in-hospital mortality substantially better than the RTS and not inferior to the MGAP and GAP. We hope that the NTS will be a useful tool for triage in trauma patients and will lead to an improvement in trauma management.

\section{Abbreviations}

AIS: Abbreviated Injury Scales; AUC: areas under the receiver operating characteristic curve; Cl: confidence interval; ED: emergency department; GAP : GCS, Age and Systolic Arterial Pressure; GCS: Glasgow Coma Scale; H-L : Hosmer-Lemeshow; ISS : Injury Severity Score; MGAP : Mechanism, GCS, and Age and Arterial Pressure; NTS: New Trauma Score; OR: odds ratio; Ps : predictive sunvival; ROC: receiver operating characteristic; RR: respiratory rate; RTS: Revised Trauma Score; SBP : systolic blood pressure; $\mathrm{SBP}_{\mathrm{NTS}}$ : code value of systolic blood pressure; $\mathrm{SPO}_{2}$ : peripheral oxygen saturation; $\mathrm{SPO}_{2 \mathrm{NTS}}$ : code value of peripheral oxygen saturation; T-NTS: New Trauma Score for Triage; TRISS: Trauma and Injury Severity Score

\section{Acknowledgements}

None.

\section{Funding}

None.

\section{Availability of data and materials}

The datasets used and analyzed during the current study are available from the corresponding author on reasonable request.

\section{Authors' contributions}

DHK, SHL and SCK designed the study. JHJ, YJP, and DHK wrote the manuscript. TYK, DL and CK extracted the data. JHJ, SBL and YJP conducted the statistical analysis. All authors were involved in drafting and critically revised the manuscript. All authors approved the final version.

\section{Ethics approval and consent to participate}

This study was approved by the Gyeongsang National University hospital institutional review board (IRB file number: GNUH 2016-09-008). The trauma registry was originally developed as a part of Emergency Department-based Injury In-depth Surveillance conducted by the Korea Centers for Disease Control and Prevention. Informed consent was not needed because the data were collected without identifiable personal information.

\section{Consent for publication}

Not applicable.

\section{Competing interests}

The authors declare that they have no competing interests.

\section{Publisher's Note}

Springer Nature remains neutral with regard to jurisdictional claims in published maps and institutional affiliations.

\section{Author details}

'Department of Emergency Medicine, Gyeongsang National University School of Medicine, 15, Jinju-daero 816beon-gil, Jinju-si, Gyeongsangnam-do 52727, Republic of Korea. '2Department of Emergency Medicine, Gyeongsang National University School of Medicine and Gyeongsang National University Changwon Hospital, Changwon, Republic of Korea. ${ }^{3}$ Institute of Health Sciences, Gyeongsang National University, 15, Jinju-daero 816beon-gil, Jinju-si, Gyeongsangnam-do, Republic of Korea.

Received: 19 February 2017 Accepted: 23 June 2017

Published online: 03 July 2017

\section{References}

1. Champion HR, Sacco WJ, Copes WS, Gann DS, Gennarelli TA, Flanagan ME. A revision of the trauma score. J Trauma. 1989;29:623-9.

2. Boyd CR, Tolson MA, Copes WS. Evaluating trauma care: the TRISS method. Trauma score and the injury severity score. J Trauma. 1987;27:370-8.

3. Joosse P, Soedarmo S, Luitse JS, Ponsen KJ. Trauma outcome analysis of a Jakarta University hospital using the TRISS method: validation and limitation in comparison with the major trauma outcome study. Trauma and injury severity score. J Trauma. 2001;51:134-40.

4. Hannan EL, Mendeloff J, Farrell LS, Cayten CG, Murphy JG. Validation of TRISS and ASCOT using a non-MTOS trauma registry. J Trauma. 1995;38:83-8.

5. Sartorius D, Le Manach Y, David JS, Rancurel E, Smail N, Thicoipe M, et al. Mechanism, Glasgow Coma scale, age, and arterial pressure (MGAP): a new simple prehospital triage score to predict mortality in trauma patients. Crit Care Med. 2010:38:831-7.

6. Kondo Y, Abe T, Kohshi K, Tokuda Y, Cook EF, Kukita I. Revised trauma scoring system to predict in-hospital mortality in the emergency department: Glasgow Coma scale, age, and systolic blood pressure score. Crit Care. 2011;15:R191.

7. Kauvar DS, Lefering R, Wade CE. Impact of hemorrhage on trauma outcome: an overview of epidemiology, clinical presentations, and therapeutic considerations. J Trauma. 2006;60:S3-11.

8. American College of Surgeons Committee on Trauma. Resources for optimal care of the injured patient. Chicago: American College of Surgeons Committee on Trauma; 2014.

9. Sasser SM, Hunt RC, Faul M, Sugerman D, Pearson WS, Dulski T, et al. Guidelines for field triage of injured patients: recommendations of the National Expert Panel on field triage, 2011. MMWR Recomm Rep. 2012;61:1-20.

10. Edelman DA, White MT, Tyburski JG, Wilson RF. Post-traumatic hypotension: should systolic blood pressure of 90-109 mmHg be included? Shock. 2007;27:134-8.

11. Hasler RM, Nuesch E, Juni P, Bouamra O, Exadaktylos AK, Lecky F. Systolic blood pressure below $110 \mathrm{~mm}$ hg is associated with increased mortality in blunt major trauma patients: multicentre cohort study. Resuscitation. 2011;82:1202-7.

12. Perry A, Potter P, Ostendorf W. Nursing Interventions \& Clinical Skills. 6th ed. St. Louis: Elsevier; 2016

13. Simoes EA, Roark R, Berman S, Esler LL, Murphy J. Respiratory rate: measurement of variability over time and accuracy at different counting periods. Arch Dis Child. 1991;66:1199-203.

14. Lovett PB, Buchwald JM, Sturmann K, Bijur P. The vexatious vital: neither clinical measurements by nurses nor an electronic monitor provides accurate measurements of respiratory rate in triage. Ann Emerg Med. 2005;45:68-76.

15. Philip KE, Pack E, Cambiano V, Rollmann H, Weil S, O'Beirne J. The accuracy of respiratory rate assessment by doctors in a London teaching hospital: a cross-sectional study. J Clin Monit Comput. 2015;29:455-60.

16. Yelderman M, New W Jr. Evaluation of pulse oximetry. Anesthesiology. 1983;59:349-52.

17. Hannhart B, Haberer JP, Saunier C, Laxenaire MC. Accuracy and precision of fourteen pulse oximeters. Eur Respir J. 1991;4:115-9.

18. Severinghaus JW, Naifeh $\mathrm{KH}$, Koh SO. Errors in 14 pulse oximeters during profound hypoxia. J Clin Monit. 1989:5:72-81.

19. Falconer RJ, Robinson BJ. Comparison of pulse oximeters: accuracy at low arterial pressure in volunteers. Br J Anaesth. 1990;65:552-7. 
20. Jay GD, Hughes L, Renzi FP. Pulse oximetry is accurate in acute anemia from hemorrhage. Ann Emerg Med. 1994;24:32-5.

21. Mower WR, Sachs C, Nicklin EL, Safa P, Baraff $\sqcup$. A comparison of pulse oximetry and respiratory rate in patient screening. Respir Med. 1996;90:593-9.

22. Woodford MR, Mackenzie CF, DuBose J, Hu P, Kufera J, Hu EZ, et al, Continuously recorded oxygen saturation and heart rate during prehospital transport outperform initial measurement in prediction of mortality after trauma. J Trauma Acute Care Surg. 2012;72:1006-11.

23. White IR, Royston $P$, Wood AM. Multiple imputation using chained equations: issues and guidance for practice. Stat Med. 2011;30:377-99.

24. Graham JW, Olchowski AE, Gilreath TD. How many imputations are really needed? Some practical clarifications of multiple imputation theory. Prev Sci. 2007:8:206-13

25. DeLong ER, DeLong DM, Clarke-Pearson DL. Comparing the areas under two or more correlated receiver operating characteristic curves: a nonparametric approach. Biometrics. 1988;44:837-45.

26. Newgard CD, Staudenmayer K, Hsia RY, Mann NC, Bulger EM, Holmes JF, et al. The cost of overtriage: more than one-third of low-risk injured patients were taken to major trauma centers. Health Aff. 2013;32:1591-9.

27. Knaus WA, Zimmerman JE, Wagner DP, Draper EA, Lawrence DE. APACHE acute physiology and chronic health evaluation: a physiologically based classification system. Crit Care Med. 1981;9:591-7.

28. Le Gall J-R, Loirat P, Alperovitch A, Glaser P, Granthil C, Mathieu D, et al. A simplified acute physiology score for ICU patients. Crit Care Med. 1984;12:975-7.

29. Vincent JL, Moreno R, Takala J, Willatts S, De Mendonça A, Bruining H, et al. The SOFA (sepsis-related organ failure assessment) score to describe organ dysfunction/failure. On behalf of the working group on sepsis-related problems of the European Society of Intensive Care Medicine. Intensive Care Med. 1996;22:707-10

30. Raum MR, Nijsten MWN, Vogelzang M, Schuring F, Lefering R, Bouillon B, et al. Emergency trauma score: an instrument for early estimation of trauma severity. Crit Care Med. 2009;17:1972-7.

31. Borgman M, Maegele M, Wade CE, Blackbourne LH, Spinella PC. Pediatric trauma BIG score: predicting mortality in children after military and civilian trauma. Pediatrics. 2011;17:e892-7.

32. Perel P, Arango M, Clayton T, Edwards P, Komolafe E, Poccock S, et al. MRC CRASH trial collaborators. Predicting outcome after traumatic brain injury: practical prognostic models based on large cohort of international patients. BMJ. 2008:336:425-9.

33. Butcher I, Maas Al, Lu J, Marmarou A, Murray GD, Mushkudiani NA, et al. Prognostic value of admission blood pressure in traumatic brain injury: results from the IMPACT study. J Neurotrauma. 2007;24:294-302.

34. Ley EJ, Singer MB, Clond MA, Gangi A, Mirocha J, Bukur M, et al. Elevated admission systolic blood pressure after blunt trauma predicts delayed pneumonia and mortality. J Trauma. 2011;71:1689-93.

35. Zafar SN, Millham FH, Chang Y, Fikry K, Alam HB, King DR, et al. Presenting blood pressure in traumatic brain injury: a bimodal distribution of death. J Trauma. 2011;71:1179-84

36. Fuller G, Hasler RM, Mealing N, Lawrence T, Woodford M, Juni P, et al. The association between admission systolic blood pressure and mortality in significant traumatic brain injury: a multi-centre cohort study. Injury. 2014;45:612-7.

37. Raux M, Thicoipe M, Wiel E, Rancurel E, Savary D, David JS, et al. Comparison of respiratory rate and peripheral oxygen saturation to assess severity in trauma patients. Intensive Care Med. 2006;32:405-12.

\section{Submit your next manuscript to BioMed Central and we will help you at every step:}

- We accept pre-submission inquiries

- Our selector tool helps you to find the most relevant journal

- We provide round the clock customer support

- Convenient online submission

- Thorough peer review

- Inclusion in PubMed and all major indexing services

- Maximum visibility for your research

Submit your manuscript at www.biomedcentral.com/submit

) Biomed Central 